\title{
Induction of Macrocyst Germination in the Cellular Slime Mould Dictyostelium mucoroides
}

\author{
By TOMOAKI ABE* AND YASUO MAEDA \\ Biological Institute, Faculty of Science, Tohoku University, Aoba, Sendai 980, Japan
}

(Received 18 April 1986; revised 28 May 1986)

\begin{abstract}
Despite the usefulness of the macrocyst cycle for genetic analysis of slime mould cells, a great difficulty has been the extremely poor germination of the macrocysts. We describe culture conditions for reliable, high-frequency macrocyst germination, using Dictyostelium mucoroides 7 (Dm7) and a mutant MF1 derived from it. Irradiation with relatively short-wavelength light (blue-near-UV) was particularly important for the induction of germination, and only a short period of irradiation was required to obtain a high percentage of germination. There was a critical temperature between 19 and $22^{\circ} \mathrm{C}$ for efficient induction of germination; a relatively high $\mathrm{pH}$, around $8 \cdot 0$, also favoured germination. Germination competence increased with the age of the macrocysts.
\end{abstract}

\section{INTRODUCTION}

Many cellular slime moulds have two developmental pathways: sorocarp formation and macrocyst formation (Raper, 1951: Blascovics \& Raper, 1957). Macrocysts are large, thickwalled, resting structures formed after the fusion of starving amoebae, and are probably sexual zygotes (Erdos et al., 1973a, b; MacInnes \& Francis, 1974; Francis, 1975; Wallace \& Raper, 1979). Some species, like Dictyostelium mucoroides, are homothallic, and the first sign of macrocyst formation is the formation of large cell aggregates in a process showing some resemblance to asexual aggregation. The aggregate is subdivided into smaller masses (precysts), each surrounded by a fibrillar sheath. A cytophagic cell (giant cell) arises at the centre of the precyst and engulfs all the other cells in the precyst to form finally the mature macrocyst surrounded by a thick wall. The environmental conditions that favour macrocyst formation differ from those favouring sorocarp formation (Weinkauf \& Filosa, 1965). Ethylene may function as a macrocyst-inducing hormone in D. mucoroides 7 and a mutant derived from it (MF1) (Amagai, 1984; Amagai \& Filosa, 1984).

A great difficulty with using this sexual cycle for genetic studies has been the extremely poor germination of the macrocysts in the laboratory, possibly because of their thick wall. Nickerson \& Raper (1973) demonstrated that light irradiation and temperatures around $15^{\circ} \mathrm{C}$ can induce macrocyst germination in $D$. mucoroides 7 . However, there have been no further reports on germination, probably because it takes a relatively long time to induce it. The present study was undertaken to determine the environmental conditions for reliably obtaining a high rate of macrocyst germination.

\section{METHODS}

Organisms and cultivation. A spontaneously occurring mutant, MF1, isolated from the wild-type strain Dictyostelium mucoroides 7 (Dm7) forms macrocysts with and without light (Filosa, 1979). MF1 was mainly used, and Dm7 for comparison. Escherichia coli $\mathrm{B} / \mathrm{r}$ was used as a food source (Bonner, 1947). Spores of MF1 were obtained from sorocarps formed either over activated charcoal on nutrient agar (Filosa, 1979), or on lactose/peptone (LP) agar without charcoal. Approximately $1 \mathrm{ml}$ of a suspension of MF1 spores together with $E$. coli was incubated at $22^{\circ} \mathrm{C}$ for $24 \mathrm{~h}$. Cells were then harvested and washed twice in $20 \mathrm{mM}$-phosphate buffer (pH 6.2). The washed cells were re-inoculated into a suspension of $E$. coli in an Erlenmeyer flask (100 ml) double 
wrapped with aluminium foil, and shaken on a rotary shaker at $22^{\circ} \mathrm{C}$. The shake culture system used was quite effective for synchronizing macrocyst formation (Filosa \& Dengler, 1972). Morphologically mature macrocysts were formed after $7 \mathrm{~d}$ of shake culture; they were washed twice in various solutions to be tested and diluted to a density of about 1000 macrocysts $\mathrm{ml}^{-1}$. Samples $(1 \mathrm{ml})$ of suspension were transferred into $3.5 \mathrm{~cm}$ diameter plastic dishes (Falcon, no. 1008). The washing and transferring procedures were done under room light as quickly as possible in order to avoid the effect of light. The preparations were sealed with Parafilm, double wrapped with aluminium foil and incubated at $22^{\circ} \mathrm{C}$ in the dark. The age of macrocysts was counted from the start of this incubation.

Light irradiation. Macrocyst samples were irradiated for various times in an incubator equilibrated at 19 or $22{ }^{\circ} \mathrm{C}$. White fluorescent lamps $(30 \mathrm{~W})$ were mainly used in addition to blue monochromatic fluorescent lamps and black-light fluorescent lamps. The light intensities to which the samples were exposed were adjusted to be almost the same for each light source.

Determination of the germination rate. After certain periods of incubation, more than 1000 macrocysts for each sample were counted under an inverted phase-contrast microscope to estimate the germination rate. In completely germinated macrocysts, only the thick wall remained as a stable structure after many cells had been released by germination. Germinating macrocysts often had a cracked wall from which part of the cell mass had moved out. These structures were regarded as germinated macrocysts. The germination rate $(\%)$ was calculated as: (no. of germinated macrocysts/total no. of macrocysts) $\times 100$. Amoebae produced by macrocyst germination again seemed to re-form macrocysts via cell aggregation during culture. Therefore, the above germination rate is considered to be an underestimate.

\section{RESULTS}

\section{Effects of $\mathrm{pH}$ and temperature on macrocyst germination}

Preliminary experiments using $20 \mathrm{~mm}$-phosphate buffer at a $\mathrm{pH}$ range of $6 \cdot 0-7 \cdot 5$ showed that increasing $\mathrm{pH}$ favoured germination, but that the rate was below $50 \%$. The germination rate was improved by the use of Good buffers instead of phosphate buffers. In all cases, light irradiation was essential for induction of germination (see below). When macrocysts of age $30 \mathrm{~d}$ were irradiated with white fluorescent lamps for $32 \mathrm{~h}$, the germination rate was low at all $\mathrm{pH}$ values examined. During prolonged irradiation $(10 \mathrm{~d})$, however, the germination rate was raised to more than $60 \%$, the highest percentage being attained in $25 \mathrm{~mm}$-Bicine buffer ( $\mathrm{pH} 8.0$ ). Thus, a relatively high $\mathrm{pH}$ seemed to favour macrocyst germination, as summarized in Table 1 .

To determine the temperature dependency of macrocyst germination, macrocysts (age $40 \mathrm{~d}$ ),

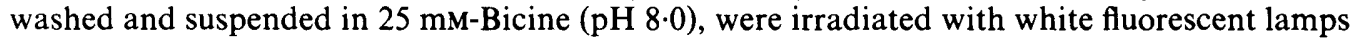
$(30 \mathrm{~W})$ for $1 \mathrm{~h}$ at $22^{\circ} \mathrm{C}$, and then incubated in the dark at temperatures from 15 to $28^{\circ} \mathrm{C}$. After $48 \mathrm{~h}$ incubation, the percentage germination rates were as follows (means $\pm \mathrm{SD}, n=5$ ): $15^{\circ} \mathrm{C}$, $65.8 \pm 3 \cdot 2 ; 19{ }^{\circ} \mathrm{C}, 71.6 \pm 2 \cdot 1 ; 22{ }^{\circ} \mathrm{C}, 28.6 \pm 3.0 ; 25^{\circ} \mathrm{C}, 28.4 \pm 2.5 ; 28{ }^{\circ} \mathrm{C}, 16.7 \pm 2.8$. These results indicate that there is a critical temperature between 19 and $22^{\circ} \mathrm{C}$ above which germination is inhibited.

\section{Induction of macrocyst germination by light irradiation}

The germination of macrocysts was quite sensitive to light, particularly of short wavelengths. When macrocysts (age $20 \mathrm{~d}$ ) were irradiated with a blue or a red monochromatic fluorescent lamp of the same strength, the blue light was quite effective in inducing germination, but the red light was almost without effect, the same as complete darkness. A black-light fluorescent lamp

\section{Table 1. Effect of pH on macrocyst germination}

Mature macrocysts of MFI were washed and suspended in the designated buffers ( $25 \mathrm{mM}$ ) and Bonner's standard salt solution (BSS; pH about 5.0). After $30 \mathrm{~d}$ incubation at $22^{\circ} \mathrm{C}$, the preparations were irradiated continuously with white fluorescent lamps $(30 \mathrm{~W})$ for the indicated times at $22^{\circ} \mathrm{C}$. The germination rates $(\%)$ were then determined, as described in Methods; the results are means of three experiments.

$\begin{array}{ccccccc}\begin{array}{c}\text { Duration of } \\ \text { irradiation }\end{array} & \begin{array}{c}\text { MES } \\ (\mathrm{pH} \mathrm{6.0)}\end{array} & \begin{array}{c}\text { PIPES } \\ (\mathrm{pH} \mathrm{6.5)}\end{array} & \begin{array}{c}\text { PIPES } \\ (\mathrm{pH} \mathrm{6.8)}\end{array} & \begin{array}{c}\text { HEPES } \\ (\mathrm{pH} \mathrm{7.5)}\end{array} & \begin{array}{c}\text { Bicine } \\ (\mathrm{pH} \mathrm{8.0)}\end{array} & \text { BSS } \\ 32 \mathrm{~h} & 21.5 & 26.0 & 26.0 & 28.3 & 31.0 & 16.1 \\ 10 \mathrm{~d} & 62.2 & 68.9 & 73.7 & 74.2 & 78.8 & 61.6\end{array}$




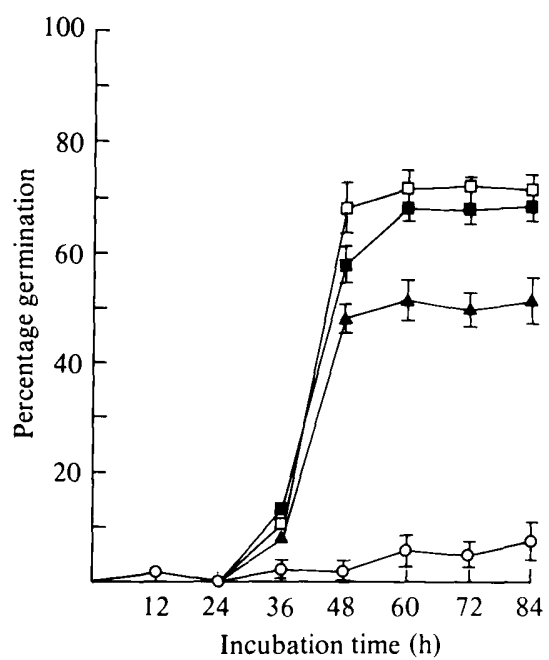

Fig. 1

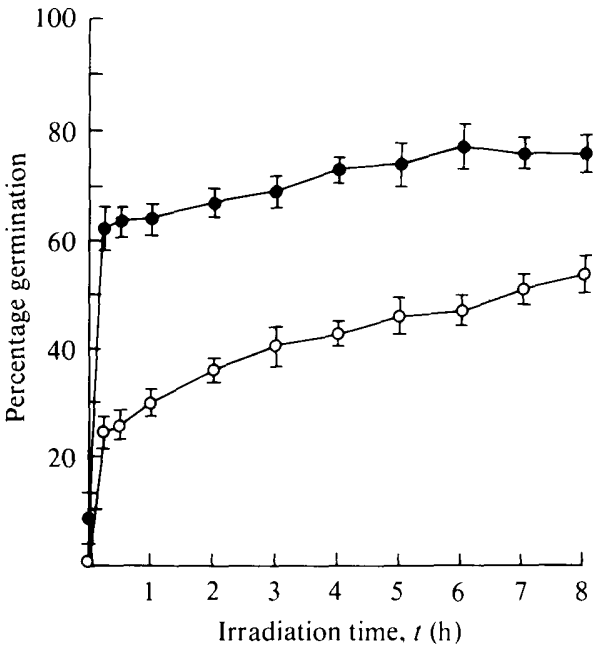

Fig. 2

Fig. 1. Induction of macrocyst germination by light. Macrocysts of MFl were incubated in $25 \mathrm{~mm}-$ Bicine (pH 8.0) for $20 \mathrm{~d}$ at $22^{\circ} \mathrm{C}$, as described in Table 1 . At age $20 \mathrm{~d}$ they were irradiated continuously for the indicated periods with white fluorescent lamps ( $\boldsymbol{\Lambda})$, blue monochromatic fluorescent lamps $(\boldsymbol{\square})$, and black-light fluorescent lamps $(\square)$ at $19^{\circ} \mathrm{C}$, followed by determination of the germination rate. As a control, the germination rate of macrocysts kept in the dark was determined $(O)$. The bars represent SD $(n=5)$.

Fig. 2. Relation of irradiation time to germination rate. Macrocysts of MF1 (age $20 \mathrm{~d}$ ) prepared as described in Fig. 1 were irradiated with blue monochromatic fluorescent lamps for the indicated periods $(t)$ at $19{ }^{\circ} \mathrm{C}(\mathrm{O})$ or $22^{\circ} \mathrm{C}(\mathrm{O})$. After 48 minus $t \mathrm{~h}$ of incubation at 19 or $22^{\circ} \mathrm{C}$ in the dark, the germination rates were determined. The bars represent $\operatorname{SD}(n=5)$.

that emitted near-UV light was slightly more effective than blue light (Fig. 1). Light-induced germination began after $24 \mathrm{~h}$ of irradiation and the rates increased rapidly during the next $24 \mathrm{~h}$. Although the wavelength of light was quite important for induction of macrocyst germination, a long period of irradiation was not necessary. The relationship between the irradiation period and germination rate is shown in Fig. 2, the germination rates being determined after $48 \mathrm{~h}(t \mathrm{~h}$ of irradiation, plus ( 48 minus $t$ ) $\mathrm{h}$ in the dark) of incubation at 19 or $22^{\circ} \mathrm{C}$. At both temperatures, almost maximal germination rates were induced by only $15 \mathrm{~min}$ irradiation, though the rate at $22^{\circ} \mathrm{C}$ was considerably lower than that at $19^{\circ} \mathrm{C}$. The germination rates increased slightly with irradiation time after $15 \mathrm{~min}$.

\section{Relation of macrocyst age to germination}

Nickerson \& Raper (1973) reported that the germination rate increased with the age of the macrocysts. To examine this more precisely, macrocysts $20 \mathrm{~d}$ and $40 \mathrm{~d}$ old were compared under the same culture conditions. The final percentage of germination was always higher in the older macrocysts, and germination also occurred about $12 \mathrm{~h}$ earlier in the older macrocysts than in the younger macrocysts (Fig. 3). In addition, the germination rate seemed to increase slowly even in the dark, this being more evident in the older macrocysts. Incidentally, germination was never induced in macrocysts of age $10 \mathrm{~d}$, at least within $48 \mathrm{~h}$ of incubation.

The above results were obtained with the mutant MF1. Essentially the same results were obtained with the wild-type strain $\operatorname{Dm} 7$ (data not shown).

\section{DISCUSSION}

Despite the usefulness of a true sexual cycle like macrocyst formation for genetic analysis of slime moulds, many genetic studies have been done by using the parasexual cycle, possibly because of the extremely poor germination of macrocysts. The data presented here show that a 


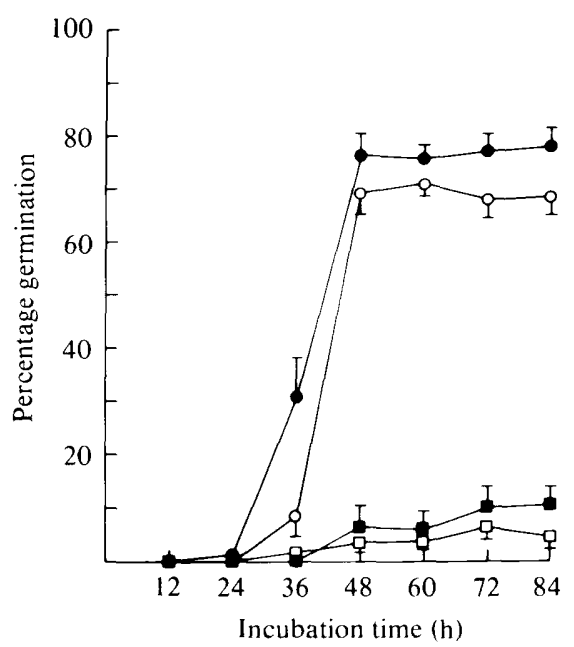

Fig. 3. Age dependency of macrocyst germination. Macrocysts of MF1, 20 or $40 \mathrm{~d}$ old, were either irradiated continuously with blue fluorescent lamps or kept in the dark for the indicated periods at $19{ }^{\circ} \mathrm{C}$, followed by determination of the germination rate. $O$, Irradiated 20-d-old macrocysts; $\bigcirc$, irradiated 40-d-old macrocysts; $\square, 20$-d-old macrocysts kept in the dark; $\square, 40$-d-old macrocysts kept in the dark. The bars represent SD $(n=5)$.

high rate (about $80 \%$ ) of macrocyst germination can be reliably attained by using improved culture conditions. In addition to a relatively high $\mathrm{pH}$, a temperature below $22^{\circ} \mathrm{C}$, and the use of aged macrocysts, irradiation with short-wavelength light (blue-near-UV) was particularly important for efficient induction of macrocyst germination. The shake culture system for obtaining macrocysts as employed in the present work was also effective for the synchronized formation and germination of macrocysts. In preliminary experiments, we used the method of Nickerson \& Raper (1973) to induce macrocyst germination, but the germination rate varied from experiment to experiment and never exceeded $50 \%$. Such a low rate of germination may at least partly be due to the relatively low $\mathrm{pH}$ of the agar plates used. It is also possible that the submerged macrocysts germinate more readily than macrocysts placed on an agar surface according to the method of Nickerson \& Raper (1973).

The importance of light and temperature for macrocyst germination, as reported by Nickerson \& Raper (1973), was confirmed by the present work. There seems to be a critical temperature around $20^{\circ} \mathrm{C}$ for germination. This raises the possibility that there may be temperature-sensitive substance(s) involved in macrocyst germination, which is (are) unstable and/or not synthesized at higher temperatures. In this connection, it is interesting that several other forms of slime mould behaviour, such as the motility and differentiation of slugs, are modulated by temperature.

There is increasing evidence that cytoplasmic $\mathrm{pH}\left(\mathrm{pH}_{\mathrm{i}}\right)$ is important in the regulation of cell differentiation and proliferation in general (Busa \& Nuccitelli, 1984; Whitaker \& Steinhardt, 1982). Cytoplasmic alkalinization has been shown to be a primary signal for the stimulation of protein synthesis after fertilization (Winkler et al., 1980). It has been claimed that $\mathrm{pH}_{\mathrm{i}}$ has a determinative effect on prespore-prestalk differentiation during asexual slime mould development (Gross et al., 1983; Inoue, 1985) and that there is a measurable difference in $\mathrm{pH}_{\mathrm{i}}$ between the two types of slug cells (Inoue, 1985). In our study, the germination of macrocysts was considerably affected by extracellular $\mathrm{pH}\left(\mathrm{pH}_{\mathrm{e}}\right)$, high $\mathrm{pH}_{\mathrm{e}}$ favouring germination. Although it is not known whether $\mathrm{pH}_{\mathrm{e}}$ may alter $\mathrm{pH}_{\mathrm{i}}$, thus resulting in a regulatory effect on germination, it would be of interest to examine the effects of $\mathrm{pH}_{e}$, light and temperature on $\mathrm{pH}_{\mathrm{i}}$, in relation to the mechanism of germination. $\mathrm{NH}_{4} \mathrm{Cl}$ acts as a weak base and elevates the $\mathrm{pH}_{\mathrm{i}}$ of aggregating D. discoideum cells (Gross et al., 1983); it would be interesting to determine the effect of $\mathrm{NH}_{4} \mathrm{Cl}$ on germination. 
A long period of light irradiation was not necessary to induce macrocyst germination. Recently, it was found that light-induced germination is completely dose-dependent, and that germination can be induced by a few seconds of irradiation ( $T$. Abe and others, unpublished). Thus macrocysts are highly sensitive to light, and purely photochemical reactions seem to be involved in their germination. We are now analysing the action spectrum to identify photoreceptors for germination. The washing of macrocysts and their transfer into plastic dishes involved a brief exposure to room light in the present work. If this process was done either in complete darkness or under a red safety light, the maximal rate of germination was at most $40 \%$ (data not shown). This clearly indicates that even at age $0 \mathrm{~d}$, some of the macrocysts are already photosensitive, brief light irradiation being a prerequisite for their germination.

The present report of conditions allowing a high rate of macrocyst germination will undoubtedly facilitate further genetic analysis and the accurate determination of the phase of meiosis during the developmental cycle of macrocysts. However, even under our conditions it still takes a relatively long time for macrocysts to acquire germination competence, and a shortening of this time is desirable. Although the detailed process of macrocyst formation in other species, such as $D$. discoideum, differs considerably from that in D. mucoroides and MF1, it will be of interest to determine whether the improved method of inducing germination is applicable to other macrocysts.

We thank Drs T. Kumagai and H. Kataoka of Tohoku University for their encouragement during the course of this study. We also gratefully acknowledge Dr A. Amagai of Kyoto University for generously providing $D$. mucoroides 7 and its mutant (MF1) and for her useful suggestions. This work was in part supported by grants-in-aid (no. 60540442) from the Ministry of Education, Science and Culture of Japan and a grant from the Yamada Science Foundation.

\section{REFERENCES}

Amagal, A. (1984). Induction by ethylene of macrocyst formation in the cellular slime mould Dictyostelium mucoroides. Journal of General Microbiology 130 , 2961-2965.

Amagai, A. \& Filosa, M. F. (1984). The possible involvement of cyclic AMP and volatile substance(s) in the development of a macrocyst-forming strain of Dictyostelium mucoroides. Development, Growth and Differentiation 26, 583-589.

Blascovics, J. C. \& RAPER, K. B. (1957). Encystment stages of Dictyostelium. Biological Bulletin 113, 58-88.

BONNER, J. T. (1947). Evidence for the formation of cell aggregates by chemotaxis in the development of the slime mould Dictyostelium discoideum. Journal of Experimental Zoology 106, 1-26.

Busa, W. B. \& Nuccitelli, R. (1984). Metabolic regulation via intracellular $\mathrm{pH}$. American Journal of Physiology 246, R409-R438.

Erdos, G. W., Nickerson, A. W. \& Raper, K. B. $(1973 a)$. The fine structure of macrocyst germination in Dictyostelium mucoroides. Developmental Biology 32, 321-330.

Erdos, G. W., Raper, K. B. \& Vogen, L. K. (1973b). Mating types and macrocyst formation in Dictyostelium discoideum. Proceedings of the National Academy of Sciences of the United States of America 70, 18281830.

FilosA, M. F. (1979). Macrocyst formation in the cellular slime mold Dictyostelium mucoroides: involvement of light and volatile morphogenetic substance(s). Journal of Experimental Zoology 207, 491-495.

Filosa, M. F. \& Dengler, R. E. (1972). Ultrastructure of macrocyst formation in the cellular slime mold, Dictyostelium mucoroides. Developmental Biology 29, 1-16.
Francis, D. (1975). Macrocyst genetics in Polysphondylium pallidum, a cellular slime mould. Journal of General Microbiology 89, 310-318.

Gross, J. D., Bradbury, J., Kay, R. R. \& Peacey, M. J. (1983). Intracellular $\mathrm{pH}$ and the control of cell differentiation in Dictyostelium discoideum. Nature, London 303, 244-245.

INOUE, K. (1985). Measurements of intracellular pH and its relevance to cell differentiation in Dictyostelium discoideum. Journal of Cell Science 76, 233245.

Macinnes, M. A. \& Francis, D. (1974). Meiosis in Dictyostelium mucoroides. Nature, London 251, 321324.

NICKERSON, A. W. \& RAPER, K. B. (1973). Macrocysts in the life cycle of the Dictyosteliaceae. II. Germination of the macrocysts. American Journal of Botany 60, 190-197.

RAPER, K. B. (1951). Isolation, cultivation, and conservation of simple slime molds. Quarterly Review of Biology 26, 169-190.

Wallace, M. A. \& Raper, K. B. (1979). Genetic exchanges in the macrocysts of Dictyostelium discoideum. Journal of General Microbiology 113, 327337.

Weinkauf, A. M. \& Filosa, M. F. (1965). Factors involved in the formation of macrocysts by the cellular slime mold, Dictyostelium mucoroides. Canadian Journal of Microbiology 11, 385-387.

Whitaker, M. J. \& SteinhardT, R. A. (1982). Ionic regulation of egg activation. Quarterly Review of Biophysics 15, 593-666.

WinkLeR, M. M., Steinhardt, R. A., Grainger, J. L. \& Minning, L. (1980). Dual ionic controls for the activation of protein synthesis at fertilization. Nature, London 287, 558-560. 